\title{
Surgical Treatment for Congenital Lung Parenchyma and Non Lung Parenchyma Disorder: Center Experience
}

Ehab Kasem ${ }^{1 *}$ and Hesham Kassem ${ }^{2}$

${ }^{1}$ Department of Thoracic and Cardiac Surgery, Zagazig University Hospital, Zagazig, Egypt

${ }^{2}$ Department of Pediatric Surgery Unite, General Surgery, Zagazig University Hospital, Zagazig, Egypt

\begin{abstract}
Objective: Non parenchyma lung disorders are rare entity with life threatening outcome. Early surgerical intervention is the clue for life saving and avoid life threatening complications.

Methods: From Aug 2008 to dec 2014, 101 cases operated in Zagazig University Hospital for congenital non parenchyma disorder data are collected regarding preoperative, intra operative and post operative results.

Results: The mean age of our patients was 27 month (1 week - 120 month). FIM 61\40. Mean symptom is respiratory distress and frequent chest infection. Tracho-esophygeal fistula 24 cases, Congenital diaphragmatic hernia 17, Diaphragmatic event ration 6, congenital lobar emphysema 37, cystic adenomatoid malformation $(n=9)$, pulmonary sequestration $(n=7)$ and arteriovenous malformation $(n=1)$
\end{abstract}

Conclusion: Early surgerical intervention for parenchyma and non parachyanma I disorder is the primary curative to avoid life threatening complications

Keywords: Congenital malformations; Lung parenchyma; Congenital cystic adenomatoid malformation; Bronchogenic cyst; Congenital diaphragmatic disorder

Abbreviation: CLE: Congenital Lobar Emphysema; CCAM: CongenitalCystic Adenomtoid Malformation;TOE:Tracheoesophageal Fistula

\section{Introduction}

Congenital disorder of thoracic content is a rare entity, with estimated annual incidence 30 to 40 cases per 100.000 populations [1]. The spectrum of these disorders include congenital lobar emphysema (CLE), congenital cystic adenomatoid malformations (CCAM), Pulmonary sequestration, anomalies of diaphragm and Tracheo-esophageal fistula [2-4]. The pathology of these disorders occurring from failure of primitive intestine and its differentiation into respiratory system [4]. The presentation of these disorders rang from respiratory failure to imaging alterations in non symptomatic adult patients [5-7]. Prenatal diagnosis is helpful in early management. [8]. CT chest is main diagnostic tool of the pathology and allow for proper surgical planning [8]. Early surgery is the principal treatment for various forms of paraenchymal and non paraenchymal lung malformations. Pulmonary resection, lobectomy being the most common procedure $[3,5,8,9]$ resections should be as conservative as possible. All pulmonary resections performed through thoracotomy. The other anomalies repaired either through thoracotomy or through abdominal incision [10].

Objective of our study present our experience with surgery in congenital lung disorder and other thoracic contents

\section{Methods}

We retrospective analysis 101 cases operated for congenital disorder of lung and other thoracic content in cardiac surgery department and pediatric surgery unit in Zagazig University Hospital from Aug 2008 to dec 2014. 107 Cases have been operated. Data analyzed regarding age, sex, symptoms of presentation and imaging test, side of the lesion and its location, surgical procedures used. post operative data include ICU, prolonged ventilation.

\section{Surgical technique}

All patients operated through thoracotomy according to affected side. Under general anaesthesia patients positioned in lateral position. Emergent consideration taken for cases of congenital lobar emphysema. Posterior thoracotomy performed in $4^{\text {th }}$ or $5^{\text {th }}$ intercostals space. surgery done according to the congenital lesion, pulmonary resection have been performed for cases of congenital lobar emphysema, reeducation of abdominal content and closure of defect with mesh used for congenital diaphragmatic hernia, placation of diaphragm for congenital event ration and for Tracheoesophageal fistula ligation of fistula. Data analyzed, mean and median age were calculated, mean length of hospital stay and percentage and location of each disease.

\section{Results}

The mean age was 4 month ( 1 week - 120 month). There was predominance of females with female to male ratio $(61 \backslash 40)$.

Mean symptom is respiratory distress except in 9 cases asymptomatic, (6 cases with CCAM, 1 case with diaphragmatic event ration, 1 lobar emphysema, 1 tracheooesophageal fistula).

The pathology and side of congenital anomaly are described in Tables 1 and 2 and for all patients chest $\mathrm{x}$ ray as routine and CT chest as confirmatory test. 11 cases required preoperative rigid bronchoscope for treatment of pneumonia (Figures 1 and 2).

17 cases had post operative complications, ( 3 pneumonia, 4 pulmonary atelectasis 3 of them require bronchoscope for respiratory care, and 6 cases had pneumothorax after ICT removal, Managed

*Corresponding author: Ehab Kasem, Assitant Professor, Department of Thoracic and Cardiac Surgery, Zagazig University Hospital, Almodeer st, Zagazig Sharkia, Egypt, Tel: 00201019495073; E-mail: ihab.kassim@yahoo.com

Received November 14, 2015; Accepted December 23, 2015; Published December 28,2015

Citation: Kasem E, Kassem H (2015) Surgical Treatment for Congenital Lung Parenchyma and Non Lung Parenchyma Disorder: Center Experience. J Pulm Respir Med 5: 306. doi:10.4172/2161-105X.1000306

Copyright: $\odot 2015$ Kasem E, et al. This is an open-access article distributed under the terms of the Creative Commons Attribution License, which permits unrestricted use, distribution, and reproduction in any medium, provided the original author and source are credited. 
Citation: Kasem E, Kassem H (2015) Surgical Treatment for Congenital Lung Parenchyma and Non Lung Parenchyma Disorder: Center Experience. J Pulm Respir Med 5: 306. doi:10.4172/2161-105X.1000306

Page 2 of 3

\begin{tabular}{|l|c|c|}
\hline & Number & $\%$ \\
\hline Congenital lobar emphysema & 37 & $36.6 \%$ \\
\hline Pulmonary sequestration & & \\
\hline Intra-pulmonary & 3 & $2.9 \%$ \\
\hline Extra pulmonary & 4 & $3.9 \%$ \\
\hline Cystic adenomatoid malformation & 7 & \\
\hline Type 1 & 1 & $6.9 \%$ \\
\hline Type 2 & 1 & $0.9 \%$ \\
\hline Type 3 & 0 & $0.9 \%$ \\
\hline Type 4 & 17 & $16.8 \%$ \\
\hline Congenital diaphragmatic hernia & 6 & $5.9 \%$ \\
\hline Congenital diaphragmatic event ration & 24 & $23.7 \%$ \\
\hline Tracheoesophageal fistula & 1 & $0.9 \%$ \\
\hline Arteriovenous malformation & &
\end{tabular}

Table 1: Pathological lesion in 101 cases.

\begin{tabular}{|l|c|c|}
\hline Side of anomalies & $\mathrm{n}$ & $\%$ \\
\hline Left upper lobe & 19 & $18.8 \%$ \\
\hline Left lower lobe & 2 & $0.198 \%$ \\
\hline Right upper lobe & 11 & $10.8 \%$ \\
\hline Right middle lobe & 10 & $9.9 \%$ \\
\hline Right lower lobe & 7 & $6.9 \%$ \\
\hline Diaphragmatic event ration & & \\
\hline Right side & 2 & $0.198 \%$ \\
\hline Left side & 4 & $3.96 \%$ \\
\hline Trcaheoesphgeal fistula & 24 & $23.7 \%$ \\
\hline Associated anomalies & 5 & $4.9 \%$ \\
\hline Congentail Diaphgramatic Herina & 17 & $16.8 \%$ \\
\hline
\end{tabular}

Table 2: Side of pathology.

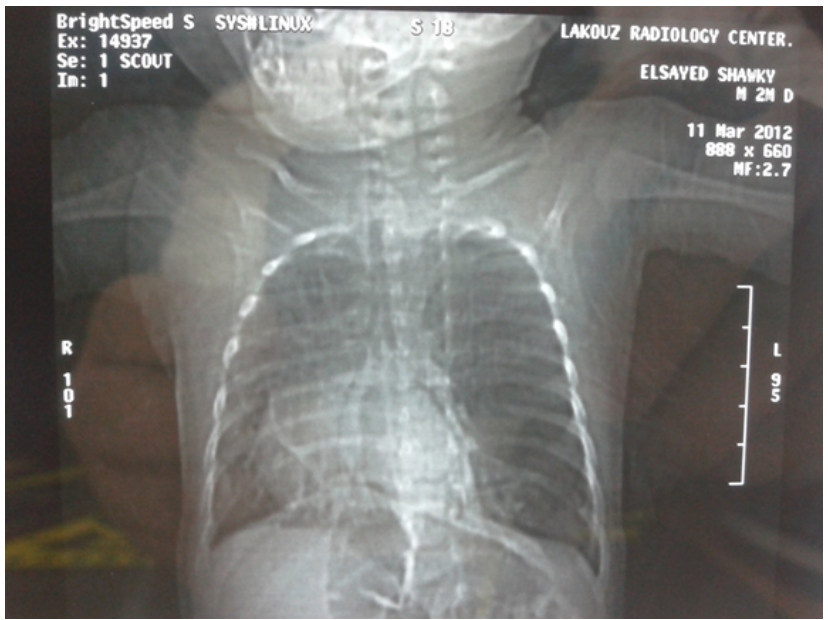

Figure 1: Congentail lobar emphysema left side.

conservative in 4 cases and 2 cases require another ICT., 4 cases has pleural effusion with re-insertion of intercostals tube).

Two patient out of 37 cases of CLE were operated while they are on mechanical ventilation, one case recovered another require prolonged mechanical ventilation die from sever respiratory infection and One case out of 24 cases of TOF was intubated and operated on mechanical ventilation. He survived after surgery.

The mean length of ICU stay was 5.4 (3-7 days) while total hospital stay was 11 day from (5-33 days) (Table 3$)$.

\section{Discussion}

Congenital anomalies of lung parenchyma and thoracic content is rare entity that require surgical intervention in majority of cases to manage the symptoms and save of remaining lung tissues (1.3.5).

The estimated annual incidence of thoracic anomaly is $30=40$ cases per 100.000 population [3] with predominance in female to male 2 to 1 [4] same we reported in our study predominance of females than males $60 \%$ of our cases are females.

Respiratory disorder is the main presentation [5-7]. However, One case of our study was discovered during routine $\mathrm{x}$-ray after traffic accident. She has diaphragmatic event ration (cases no 91). Recently many of cases diagnosed during prenatal care and so decision can be taken early or after close observation.

Imaging of chest has great role in diagnosis. Routine chest ray give high suspicious and CT of chest imaging is confirmatory tool for the pathology and role out differential diagnosis [6,7].

Surgery is the curative tool of diagnosed cases. Surgical strategy according to diagnosis case with (CLE) surgery go with symptoms, cases with mild symptoms require follow up while symptomatic cases planned for surgery, lobecttomy is the main main surgery depened on affected lobe. While cases with (CACM), Asymptomatic cases require close observation and fellow up to manage symptoms and avoid complications as in cystic adenoid malformation to avoid malignancy (bronchio alveolar carcinoma, rhabdomyosarcoma) [11,12]. No surgery carried as prophylactic for our cases, surgery is indicated on symptoms.

Pulmonary resection is the main surgical procedure for diagnosed

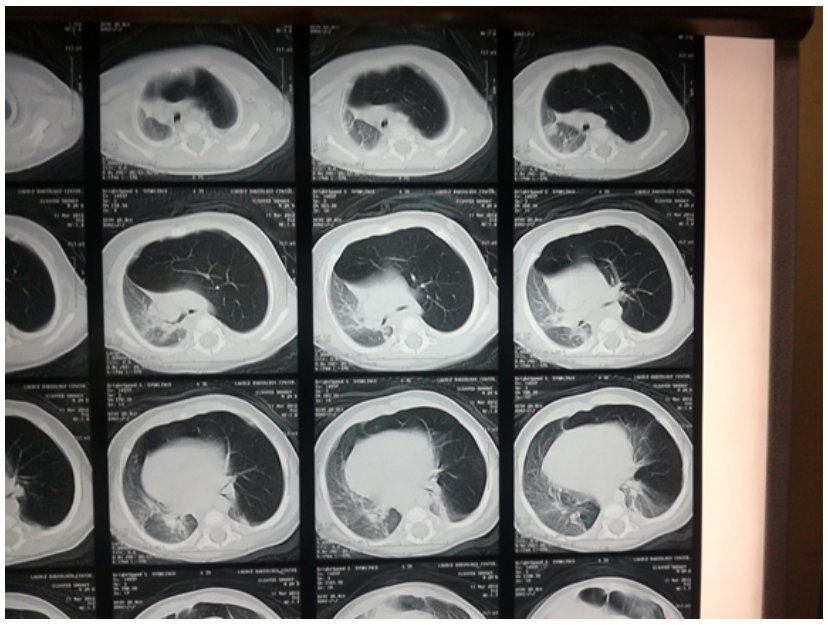

Figure 2: CT of congentail lobar emphysema.

\begin{tabular}{|l|c|c|}
\hline Post operative complications & $\mathbf{n}$ & $\%$ \\
\hline Pneumonia & 3 & $2.9 \%$ \\
\hline Atelectasis & 4 & $3.9 \%$ \\
\hline Pneumothorax & 1 & $0.09 \%$ \\
\hline Pleural effusion & 2 & $0.198 \%$ \\
\hline Mortality & 1 & $0.9 \%$ \\
\hline Mean ICU stay & $11(5-33)$ day & \\
\hline Mean hospital stay & $5.4(3-7)$ day & \\
\hline
\end{tabular}

Table 3: Post operative complications. 
Citation: Kasem E, Kassem H (2015) Surgical Treatment for Congenital Lung Parenchyma and Non Lung Parenchyma Disorder: Center Experience. J Pulm Respir Med 5: 306. doi:10.4172/2161-105X.1000306

case of congenital lobar emphysema, intra-pulmonary sequestration and congenital cystic adenomatoid malformation. While for extra pulmonary sequestration, sequestrectomy is indicated [13-16].

Congentail cystic adenomatid malformation (CAM) SURGERY is indicated for symptoms or to avoid malignant incidence, surgery in form of lobectomy $[17,18]$.

For cases diaphragmatic event ration, placation of diaphragm form thoracic side done $[19,20]$ surgery is done once diagnosis confirmed and cases with tracheoesophgeal fistula surgery is done through right throcaotomy in 19 cases and by neck incision for $\mathrm{H}$ type fistula [21-23].

Three cases of TOF have right aortic arch [24]. In our study we operate through thoracotomy according to affected side and we use $4^{\text {th }}$ or $5^{\text {th }}$ space according to affected lobe. Although in many center videoassisted thoracoscopy has been widely used for pulmonary resection. Upper pulmonary resection is most common type of resection for cases of CLE, while for cases of CAM, lower lobectomy is used as many studies $[11-13,15,17]$

We reported 5 cases with combined anomalies three cases with right aortic arch in cases of TOF, one case with right coronary artery fistula to right atrium and one case with deformed chest wall pectus excavatum. Some studies reported higher incidence of mixed pulmonary malformation which is not reported in our study and also reported high incidence of cardiac, esophageal and chest wall malformation, but the incidence in our study is lower than reported.

The reported post operative complications are mainly pleural in term of pneumothorax and parenchyma in form of atelectasis which require bronchoscope for management. This also reported in many series [13-15] which reported high incidence of pleural complications after pulmonary resection.

\section{Conclusion}

Surgery is the clue for congenital parenchyma lung disorder and non parenchyma disorder, surgery is applied as diagnosis confirmed carry the advantages of saving lung parenchyma and avoid life threatening complications or malignant conversion in some anomaly like CAM.

\section{Acknowledgment}

We want to express our appreciation to Dr. Nader Abdul Raheim Fayed for his valuable advise and great support.

\section{References}

1. Parikh D, Samuel M (2005) Congenital cystic lung lesions: Is surgical resection essential? Pediatr Pulmonol 40: 533-537.

2. Al-Salem AH (2002) Congenital lobar emphysema. Saudi Med J 23: 335-337.

3. Colon N, Schlegel C, Pietsch J, Chung DH, Jackson GP (2012) Congenital lung anomalies: can we postpone resection? J Pediatr Surg 47: 87-92.

4. Zach MS, Eber E (2001) Adult outcome of congenital lower respiratory tract malformations. Thorax 56: 65-72.

5. Salzberg AM, Krummel TM (1990) Congenital malformations of the lowe respiratory tract. In: Chernick V, Kendig EL (eds.) Disorders of the respiratory tract in children. Philadelphia: Saunders 227-67.

6. Clements BS (1999) Congenital malformations of the lungs and airways. In: Taussig LM, Landau LI (eds.) Pediatric respiratory medicine. St. Louis: Mosby pp. 1106-36

7. Duan M, Wang L, Cao Y, Li Z, Yang W, et al. (2005) Results of surgical treatment of congenital cystic lung disease. Thorac Cardiovasc Surg 53: 61-64.

8. Laberge JM, Flageole H, Pugash D, Khalife S, Blair G, et al. (2001) Outcome of the prenatally diagnosed congenital cystic adenomatoid lung malformation: a Canadian experience. Fetal Diagn Ther 16: 178-186.

9. Vogt-Moykopf I, Rau B, Branscheid D (1992) Surgery for congenital malformations of the lung. Ann Chir 46: 141-156.

10. Ferreira HP, Fischer GB, Felicetti JC, Camargo Jde J, Andrade CF (2010) [Surgical treatment of congenital lung malformations in pediatric patients]. $\mathrm{J}$ Bras Pneumol 36: 175-180.

11. Lakhoo K (2009) Management of congenital cystic adenomatous malformations of the lung. Arch Dis Child Fetal Neonatal Ed 94: F73-76.

12. Ashcraft KW, Murphy JP, Sharp RL (2000) Bronchopulmonary malformations Pediatric Surgery (3rdedn) Philadelphia PA: WB Saunders: 273-286.

13. Bratu I, Flageole H, Chen MF, Di Lorenzo M, Yazbeck S, et al. (2001) The multiple facets of pulmonary sequestration. J Pediatr Surg 36: 784-790.

14. Roberts PA, Holland AJ, Halliday RJ, Arbuckle SM, Cass DT (2002) Congenital lobar emphysema: Like father, like son. J Pediatr Surg 37: 799-801.

15. Thakral CL, Maji DC, Sajwani MJ (2001) Congenital lobar emphysema: experience with 21 cases. Pediatr Surg Int 17: 88-91.

16. Somja J, De Leval L, Boniver J, Radermecker MA (2011) [Clinical case of the month. Intrapulmonary lung sequestration diagnosed in an adult]. Rev Med Liege 66: 7-12.

17. Yagyu $H$, Adachi $H$, Furukawa K, Nakamura $H$, Sudoh A, et al. (2002) Intralobar pulmonary sequestration presenting increased serum CA19-9 and CA125. Intern Med 41: 875-878.

18. Gezer S, Taştepe I, Sirmali M, Findik G, Türüt H, et al. (2007) Pulmonary sequestration: a single-institutional series composed of 27 cases. J Thorac Cardiovasc Surg 133: 955-959.

19. Freeman RK, Van Woerkom J, Vyverberg A, Ascioti AJ (2009) Long-term follow-up of the functional and physiologic results of diaphragm plication in adults with unilateral diaphragm paralysis. Ann Thorac Surg 88: 1112-1117.

20. Fisher JC, Haley MJ, Ruiz-Elizalde A, Stolar CJ, Arkovitz MS (2009) Multivariate model for predicting recurrence in congenital diaphragmatic hernia. J Pediatr Surg 44: 1173-1179.

21. Keller RL, Tacy TA, Hendricks-Munoz K, Xu J, Moon-Grady AJ, et al. (2010) Congenital diaphragmatic hernia: endothelin-, pulmonary hypertension, and disease severity. Am J Respir Crit Care Med 182: 555-561.

22. Holder TM, Ashcraft KW, Sharp RJ, Amoury RA (1987) Care of infants with esophageal atresia, tracheoesophageal fistula, and associated anomalies. Thorac Cardiovasc Surg 94: 828-835

23. Ayed AK, Owayed A (2003) Pulmonary resection in infants for congenital pulmonary malformation. Chest 124: 98-101.

24. Albanese CT, Sydorak RM, Tsao K, Lee H (2003) Thoracoscopic lobectomy for prenatally diagnosed lung lesions. J Pediatr Surg 38: 553-555. 